\title{
Efficacy and safety of pleurectomy and wedge resection versus simple pleurectomy in patients with primary spontaneous pneumothorax
}

\author{
Agata Díeljilji ${ }^{1}$, Krzysztof Karuś ${ }^{1}$, Artur Kierach ${ }^{2}$, Barbara Kazanecka ${ }^{3}$, Wojciech Rokicki ${ }^{4}$, \\ Witold Tomkowski ${ }^{3}$
}

${ }^{1}$ Department of Thoracic Surgery, National Institute of Tuberculosis and Lung Diseases (NITLD), Warsaw, Poland; ${ }^{2}$ Kierach Clinic, Tychy, Poland; ${ }^{3}$ Cardio-Pulmonary Intensive Care Department, National Institute of Tuberculosis and Lung Diseases (NITLD), Warsaw, Poland; ${ }^{4}$ Department of Thoracic Surgery, School of Medicine with the Division of Dentistry in Zabrze, Medical University of Silesia, Katowice, Poland

Contributions: (I) Conception and design: A Dżeljilji; (II) Administrative support: W Rokicki, W Tomkowski; (III) Provision of study materials or patients: All authors; (IV) Collection and assembly of data: A Dżeljilji, K Karuś, A Kierach, B Kazanecka; (V) Data analysis and interpretation: B Kazanecka; (VI) Manuscript writing: All authors; (VII) Final approval of manuscript: All authors.

Correspondence to: Agata Dżeljilji, MD, PhD. Department of Thoracic Surgery, National Institute of Tuberculosis and Lung Diseases (NITLD), Warsaw, Poland. Email: nosearmy85@gmail.com.

Background: The treatment of primary spontaneous pneumothorax (PSP) remains controversial. Guidelines do not explicitly define surgical procedures. Different treatment modalities are observed in clinics of same profile. Treatment is controversial. The aim of the work was to compare the effectiveness of two methods-pleurectomy and pleurectomy combined with wedge resection in patients with PSP in terms of safety and efficiency.

Methods: Non-randomized observational study based on clinical analysis of 73 patients, M:F ratio 3:1, aged 18 to 45 years, the average age was 29 years, operated between January 2008 and December 2014 due to the occurrence of PSP. Pleurectomy was supplemented by wedge resection in patients diagnosed intraoperatively with ELC (emphsema-like changes) $\geq$ III stage (classification of PSP by Vanderschueren). Efficacy was defined as follows: complete lung expansion, drainage (days), air leak, frequency of PAL (persistent air leak $>5$ days), recurrences and re-operations. Safety was defined as follows: heamothorax, major bleeding (loss of $\mathrm{Hg}>2 \mathrm{~g} / \mathrm{dL}$ ), infections, deaths. The research project was approved by the Bioethical Commission of the Silesian Medical University in Katowice (KNW/022/kb1/3/14).

Results: Mean follow-up was 22 months. Efficacy: recurrences occurred less frequently in group treated with pleurectomy without wedge resection. No results were found in other parameters. Safety: No results were found in all parameters.

Conclusions: Efficacy and safety of pleurectomy vs. pleurectomy + wedge resection is comparable.

Keywords: Pneumothorax; pleurectomy; thoracoscopy

Submitted Jun 19, 2019. Accepted for publication Oct 17, 2019.

doi: $10.21037 /$ jtd.2019.11.28

View this article at: http://dx.doi.org/10.21037/jtd.2019.11.28

\section{Introduction}

Patients with stage I [classification of primary spontaneous pneumothorax (PSP) by Vanderschueren] (Table 1) are treated with pleurectomy or pleurodesis, while in stage III and IV the patients are additionally treated with lung wedge resection. Vanderschueren's classification is often used to determine the extent of morphologic lung alteration for spontaneous pneumothorax. This classification consists of four different stages: stage I: no endoscopic abnormalities (normal findings), stage II: pleuropulmonary adhesions, 


\begin{tabular}{ll} 
Table 1 Abbreviations and acronyms \\
\hline Acronyms & Full spelling \\
\hline PSP & Primary spontaneous pneumothorax \\
VATS & Video-assisted thoracoscopic surgery \\
P & Pleurectomy \\
PD & Mechanical pleurodesis \\
PC & Chemical pleurodesis \\
ELC & Emphysema-like changes \\
WR & Wedge resection \\
AATD & Alpha-1 antitrypsin deficiency \\
PAL & Persistent air leak \\
BTS & British Thoracic Society \\
OR & Odds ratio \\
CI & Confidence interval \\
SD & Standard deviation \\
\hline
\end{tabular}

stage III: blebs/bullae less than $2 \mathrm{~cm}$ in diameter, and stage IV: bullae more than $2 \mathrm{~cm}$ in diameter (1).

The surgical treatment available is only symptomatic. Simple pleurectomy does not prevent the formation of blebs. Chest surgeons, even if they are able to detect blebs in their typical locations, have difficulties detecting air leak. Hence the often-emerging doubts about the effectiveness and safety of additional lung wedge resection.

The guidelines do not explicitly define surgical procedures (2-6).

The aim of this study was to evaluate the efficacy and safety of chest wall pleurectomy in the treatment of PSP.

\section{Methods}

We performed a prospective consecutive study involving all patients with PSP, who underwent VATS pleurectomy from top to the diaphragm. Seventy-three patients were operated on in The Department of Thoracic Surgery in Zabrze, in the period from January 2008 to December 2014, with the implementation of thoracoscopic chest wall pleurectomy, 33 (45.21\%) of which had wedge lung resection performed additionally.

The study was reviewed and approved by Ethical Committee of SUM and individual patient consent was waived (KNW/022/kb1/3/14).

The surgical indications included were as follows:
(I) Recurrent spontaneous pneumothorax on the same side;

(II) Lack of full lung expansion;

(III) PAL—persistent air leak $>5$ days;

(IV) Considering patient preference (profession, access to professional medical care).

Exclusion criteria:

(I) Pathological changes within the pulmonary parenchyma, which may indicate SSP (secondary spontaneous pneumothorax);

(II) Fluid in the pleural cavity;

(III) Infection;

(IV) Family occurrence of PSP.

Fifty-six men (76.71\%) and 17 women (23.29\%) aged 18 to 45 years, M:F ratio 3:1 were treated and the average age was 29 years. Patients in the age group 18-24 years of age were predominant among men, and 25-34 years of age among women. Sixty persons $(82.20 \%)$ of the analyzed group had never smoked tobacco. Former smokers accounted for $17.80 \%$ of the group ( $n=13)$. A recurrent pneumothorax was found in $27(36.99 \%)$ patients (Table 2).

In all patients, the onset of symptoms of pneumothorax was not associated with increased physical activity. In 42 (57.53\%) patients the symptoms appeared while watching $\mathrm{TV}$, reading and sleeping, in $26(35.62 \%)$ during a walk, and in $5(6.85 \%)$ while performing household activities not associated with intense physical activity.

Sudden chest pain was reported by 66 (85\%) patients.

The main 55 -person (71.4\%) group of patients referred to the Clinic were those in whom no lung expansion was attempted before the admission to the clinic, some were treated at other centers using conservative methods (observation of pneumothorax, oxygen therapy, physiotherapy).

The second-a significantly smaller group of 18 $(24.66 \%)$-were the patients in which lung expansion by pleural drainage or repeated puncture of the chest was attempted during the first 48 hours from the onset of emphysema. The treatment turned out to be ineffective in both cases.

Thirty-three (45.21\%) of the patients from the study group did not seek medical assistance immediately after the onset of symptoms. The average time elapsed from the onset of symptoms of pneumothorax to surgery was 3.4 days.

No changes in the lung parenchyma were shown in CT of the chest in majority of the patients $(\mathrm{n}=53,72.60 \%)$. The remaining 20 (27.40\%) patients had ELC. Pneumothorax 
Table 2 Demographic and clinical characteristic of patient with PSP who underwent surgical treatment with pleurectomy vs. pleurectomy with wedge resection

\begin{tabular}{lccc}
\hline Characteristic & Group: pleurectomy, $\mathrm{n}(\%)$ & Group: pleurectomy + wedge resection, $\mathrm{n}(\%)$ & $\mathrm{P}$ value/ $\chi^{2}$ test/t-test \\
\hline Total & $40(54.79)$ & $33(45.21)$ & $\mathrm{P}=0.861 ; \chi^{2}=0.031$ \\
Sex, male & $31(77.50)$ & $25(75.76)$ & $\mathrm{P}=0.578 ; \mathrm{t}=0.559$ \\
Age, mean \pm SD (years) & $27.38 \pm 8.03$ & $26.48 \pm 4.8$ & $\mathrm{P}<0.001 ; \chi^{2}=19.172$ \\
Smokers & 0 & $13(39.39)$ & $\mathrm{P}=0.065 ; \chi^{2}=3.417$ \\
First incident of PSP & $29(72.50)$ & $17(51.52)$ & $16(48.48)$ \\
Recurrent PSP & $11(27.50)$ & & \\
\hline
\end{tabular}

PSP, primary spontaneous pneumothorax.

on the right side in $45(61.64 \%)$ patients, all patients had pneumothorax $>2 \mathrm{~cm}, 10.95 \%$ of patients had total lung collapse.

The following parameters were determined:

(I) Evaluation of lung expansion after surgery;

(II) The percentage of postoperative complications;

(III) Reoperations;

(IV) Recurrences.

Follow-up was complete in all patients. Follow-up information was obtained from the hospital case records and from questionnaire completed.

Mean follow-up was 22 months.

\section{Surgical care}

Surgical procedures were performed using videothoracoscopy method in accordance with current applicable standards.

Nearly half of the patients $(n=33,45.21 \%)$ had emphysema-like changes found intraoperatively. In most cases, they did not exceed $20 \mathrm{~mm}$ (stage III classification of PSP by Vanderschueren). One patient had $60 \mathrm{~mm}$ emphysema (stage IV classification of PSP by Vanderschueren). Individual changes were observed in $18(54.5 \%)$ patients, multiple in 15 (45.5\%). The most common location was the peak area of the upper lobe (70\%), less common was the peak posterior area of the lower lobe $(22 \%)$ and the changes were observed in other peripheral areas of the lung (8\%) in individual cases.

Almost complete removal of the parietal pleura was performed in all patients (100\%), and in $33(45.21 \%)$ patients diagnosed with ELC the treatment was extended with resection of macroscopically changed lung parenchyma with the use of a stapler.

Pathology postoperatively confirmed blebs/bullae in all specimens.

The duration of the procedure was $68 \mathrm{~min}$ on average, SD $8.2,(40-75 \mathrm{~min})$.

A single drainpipe $\left(28-30^{\circ} \mathrm{F}\right)$ was inserted into the pleural cavity following the completion of the intervention. For the first day, suction drainage with the force of up to $-20 \mathrm{cmH}_{2} \mathrm{O}$ was used. Post surgery, all patients underwent $\mathrm{X}$-ray, received anticoagulant therapy, analgesics and antibiotics (amoxicillinum + acidum clavulanicum + $2 \times 1.2$ g i.v.), some patients received passive oxygen therapy. The indications for the removal of the catheter from the pleural cavity were: failure to find pulmonary leak within 24 hours of observation and drainage $\leq 100 \mathrm{~mL}$ of clear fluid. After removing the drains, radiological follow-up was performed. In the absence of full lung expansion, the decision on further procedure depended on the size of the collapse of the lung.

\section{Statistics}

The results of the laboratory tests and clinical studies were prepared using the elements of descriptive statistics (arithmetic mean, standard deviation, median, minimum, maximum) and presented in the form of tables.

Statistical inference was done using the following:

* Student's $t$-test;

* ANOVA (analysis of variance);

* Mann-Whitney test;

* Correlation coefficient; where correlation was statistically significant, direction and strength of the relationship was determined.

- $\mathrm{P}<0.05+$;

- $\mathrm{P}<0.02++$

- $\mathrm{P}<0.01+++$; 
Table 3 Efficacy results of surgical treatment for PSP

\begin{tabular}{|c|c|c|c|c|c|}
\hline Factor & $\begin{array}{c}\text { Group: pleurectomy, } \\
\text { n (\%) }\end{array}$ & $\begin{array}{c}\text { Group: pleurectomy + } \\
\text { wedge resection, n (\%) }\end{array}$ & Odds ratio & $95 \% \mathrm{Cl}$ & $\mathrm{P}$ value/t-test \\
\hline Complete lung expansion & $37(92.50)$ & 30 (90.91) & 1.233 & $0.232-6.559$ & $P=0.816$ \\
\hline Air leak, mean $\pm \mathrm{SD}$ (days) & $7(17.50)$ & $5(15.62)$ & 0.873 & $0.249-3.063$ & $P=0.846$ \\
\hline
\end{tabular}

PSP, primary spontaneous pneumothorax.

- $\mathrm{P}<0.001++++$.

Drainage (presented with days) did not have a normal distribution in the analyzed groups (P from the ShapiroWilk test below 0.05 ), so the analysis was carried out with the Mann-Whitney test.

The occurrence of haemothorax, major bleeding (loss of $\mathrm{Hg}>2 \mathrm{~g} / \mathrm{dL}$ ) and reoperation were analyzed using OR (odds ratio).

In the case of PAL (persistent air leak $>5$ days) and recurrences of PSP, they occurred only in one of the groups, which made it impossible to calculate the OR. The significance of the differences between the groups was therefore checked by Fisher's exact test.

All statistics were calculated for significance level of 0.05 .

All analytes were performed using a single open-source software package [R Development Core Team, $2009(7,8)]$.

\section{Results}

\section{Efficacy}

The radiological post-surgery follow-up revealed incomplete expansion of the lungs in $6(8.21 \%)$ patients. There was no statistically significant correlation between the range of surgery performed and the degree of the expansion of the lung $(\mathrm{P}=0.816)$.

In patients in whom there were no postoperative complications, average drainage was $100 \mathrm{~mL} /$ day. In the group in which there were complications on the other hand, drainage was maintained for an average of 7 days, the amount of drained fluid was significantly higher and amounted to approx. $250 \mathrm{~mL} /$ day. No statistically significant correlation between additional resection of ELC with a stapler and the time duration of the drainage was found $(\mathrm{P}=0.926)$.

No significant statistical significance $(\mathrm{P}=0.848)$ was found between the additional resection of the changed lung parenchyma with a stapler, and the occurrence of postoperative air leak $(\mathrm{OR}=0.873,95 \% \mathrm{CI}=0.249-3.063$, $\mathrm{P}=0.846$ ). There was no statistically significant difference in the duration of air leak $(\mathrm{P}=0.577)$ and the incidence of PAL $(\mathrm{P}=0.245)$. Pulmonary air-leak was observed in 12 $(16.44 \%)$ patients. More than half of the patients $(n=9$, $69 \%$ ) had spontaneous closure of the leak before 5 days. Three patients (25\%) with persistent PAL were qualified for pleural cavity revision. Recurrences were more frequent in the group of patients treated with pleurectomy + wedge resection $(\mathrm{P}=0.04)$ (Table 3).

\section{Safety}

Haemothorax was found in $9(12.32 \%)$ patients. Based on the obtained data, it was demonstrated that the additionally performed wedge lung resection did not increase the risk of haematoma in the postoperative period $(\mathrm{P}=0.145)$. Major bleeding $(\mathrm{Hg}>2 \mathrm{~g} / \mathrm{dL})$ occurred with similar frequency in both groups $(\mathrm{P}=1)$. Five patients were treated with puncture, average of $300 \mathrm{~mL}$ of bloody content was collected, and in the other four haemothorax was the indication for the revision of the pleural cavity with access via thoracotomy.

In total, 7 (9.59\%) patients were reoperated, the scope of the procedure did not increase the risk of reoperation $(\mathrm{P}=0.116)$. No infections or deaths occurred within the study group (Table 4).

\section{Comments}

The exclusion criteria are not contraindication for surgery. However, for this patient in fear to complications, such as reoperation we conduct pleurodesis.

Re-examination of the pleural cavity due to the produced 
Table 4 Safety results of surgical treatment for PSP

\begin{tabular}{lcccc}
\hline Factor & $\begin{array}{c}\text { Group: pleurectomy, } \\
\mathrm{n}(\%)\end{array}$ & $\begin{array}{c}\text { Group: pleurectomy }+ \\
\text { wedge resection, } \mathrm{n}(\%)\end{array}$ & Odds ratio & $95 \% \mathrm{Cl}$ \\
\hline Haemothorax & $7(17.5)$ & $2(6.06)$ & 0.295 & $0.057-1.526$ \\
Major bleeding $\mathrm{Hg}>2 \mathrm{~g} / \mathrm{dL}$ & $1(1.36)$ & $1(1.36)$ & 1.182 & $0.071-19.636$ \\
Infections & 0 & 0 & - & - \\
Re-operations & $6(8.21)$ & $1(1.36)$ & 0.172 & $0.02-1.505$ \\
Deaths & 0 & 0 & - & - \\
\hline
\end{tabular}

PSP, primary spontaneous pneumothorax.

pleural-pulmonary adhesions is very difficult. These patients were excluded due to possible negative effect on the treatment outcome (presence of fluid in the pleural cavity points to the extended period from the occurrence of pneumothorax to expansion of the lungs). Patients with family history of PSP may constitute a separate group of patients. We excluded also patients with infection and pathological changes within the pulmonary parenchyma, which may indicate SSP.

Based on the obtained results, we conclude that both methods do not differ from each other. In our study wedge resection was performed upon detection of bullae or air leak in the course of the operation (therefore in stage III and IV patients). The choice was dictated by higher recurrence rates in those groups of patients. We did not do routine wedge resection. Benefits of such conduct have been reported in literature. Within the selected group of patients with PSP in stage I (no endoscopical abnormalities) in group of patients who underwent pleurectomy accompanied by apical lung wedge resection, no recurrences were observed $(\mathrm{P}=0.009)$ (9). However in stage $\mathrm{I}$, the frequency of relapses is very low. This method is not widespread because of the very low incidence of recurrences in stage $\mathrm{I}$, and the possibility of ELC (emphysema like changes) occurrences in different regions of the lung. In the study recurrences is seen among the cohort with wedge resection. In our opinion this reflects the severer condition of this cohort.

PAL is a major problem in treatment. The incidence of PAL was $5.48 \%$ and the results are consistent with observations of other authors $(5-7 \%)(10,11)$. The relatively high incidence of PAL in the postoperative period could not be explained only by improper technique of resection of the changed pulmonary parenchyma. In addition, performing resection of the altered parenchyma did not increase the risk of postoperative complications, including PAL. This is also consistent with the study by Jiang et al. (12). According to the British recommendations, PAL lasting over 5 days is an indication for reoperation. This procedure was also adopted at the Clinic in Zabrze, even though 69\% (9/12) patients had spontaneous resolution of air leak before the lapse of 5 days. Chee et al. showed in their work on a group of 130 patients that PAL resolves spontaneously in $100 \%$ before the lapse of 14 days (13). Because of this observation, we believe that it is worthwhile to reassess the indications for reoperation because of PAL. Wedge resection using a stapler is a safe method. We encourage to carefully search for ELC within the pulmonary parenchyma and to perform its resection.

However, bullectomy alone does not significantly reduce the rate of PSP recurrences after operative treatment. This is also consistent with the study by Loubani (14) and Sahn (15).

The possibility of the occurrence of emphysemal changes in various parts of the lungs confirmed by studies is-in our opinion-a valuable observation. Diversification of treatment methods applies both to the techniques of pleuropulmonary symphysis formation and pulmonary pleura irritation. The possibility of the occurrence of emphysemal changes in various parts of the lungs draws attention to the extent of the irritation of the pleural wall as an important factor affecting the effectiveness of the treatment.

The high percentage of patients should be noted, in whom there were no changes found in the lung parenchyma (72\%). Multi-row imaging with layer thickness of $2 \mathrm{~mm}$ was analyzed in the study group. The protocol used shows high effectiveness of blebs detection of over $80 \%$ (16-18). However, ruptured emphysema blebs as places of leakage were found in the study group during surgery. Such cicatricial changes are difficult to visualize in CT. This is most likely the cause of the variance in results. Our results also indicate that the decision to qualify for surgery should 
not be dependent upon the presence blebs in the CT image. We would like to add, that in the past few years, new improved thoracoscopic methods emerged using contrast agents that increase the detection rate of ELC during surgical procedures $(19,20)$. It may reduce the chances of PAL in the postoperative period.

The percentage of postoperative complications in the study group was $17.8 \%$. According to BTS Guidelines 2010 (2), they should not exceed 16\%. The reason for the high percentage of complications is the increased risk of bleeding associated with the use of the wall pleurectomy method. In the study group, pleural hematoma occurred in $9(12.32 \%)$ of patients, in 4 it was an indication for reoperation.

Haematoma of the pleural cavity should occur as infrequently as possible and does not exceed $1.5 \%$ after mechanical pleurodesis $(10,11)$. Re-revision of the pleural cavity is a big burden for the patient. After wall pleurectomy, relapses were observed in $5.5 \%$ of patients. The patients did not require reoperation. The efficacy is comparable to the results of $\mathrm{PD}$ and $\mathrm{PC}$ treatment methods. The results of a large meta-analysis covering 542 articles from 2000-2011 confirm that pleurodesis and pleurectomy methods can compete with each other (21). Chen et al. found that pleural abrasion with minocycline pleurodesis is as effective as apical pleurectomy, 3.8\% and $3.8 \%$ respectively (22). Sepehripour et al. have confirmed that mechanical and chemical pleurodesis in combination with bleb resection show comparable results as complete removal of the parietal pleura (23). An opposite view was expressed by Huh together with colleagues he demonstrated superior efficacy of pleurectomy limited only to the top over mechanical pleurodesis, $9.1 \%$ and $12.3 \%$ respectively $(\mathrm{P}=0.01)$ (24).

Conflicting research results and better results/improving of PD and PC treatment methods confirm the need to conduct new research to accurately assess the efficacy of the available methods of pleuropulmonary symphysis formation and to determine the factors favorably influencing the effects of treatment.

The results indicate the need to increase the safety of the treatments. Due to the above, we criticize the wall pleurectomy procedure and we encourage limiting its performance. Before applying a more aggressive method like the excision of the pleural wall, pleurodesis should be the first choice, especially in young patients with benign disease and good prognosis.

Within the study group, antibiotics were administered to all patients during the postoperative period. There was no infection in the operated patients. In the literature, this complication may be as high as $7 \%(10,11)$. No results were found in other parameters.

\section{Acknowledgments}

None.

\section{Footnote}

Conflicts of Interest: The authors have no conflicts of interest to declare.

Ethical Statement: The authors are accountable for all aspects of the work in ensuring that questions related to the accuracy or integrity of any part of the work are appropriately investigated and resolved. The study was reviewed and approved by Ethical Committee of SUM and individual patient consent was waived (KNW/022/ $\mathrm{kb} 1 / 3 / 14)$.

\section{References}

1. Vanderschueren RG. The role of thoracoscopy in the evaluation and management of pneumothorax. Lung 1990;168:1122-5.

2. Baumann MH, Strange C, Heffner JE, et al. AACP Pneumothorax Consensus Group Management of spontaneous pneumothorax: an American College of Chest Physicians Delphi consensus statement. Chest 2001;119:590-602.

3. MacDuff A, Arnold A, Harvey J, BTS Pleural Disease Guideline Group Management of spontaneous pneumothorax: British Thoracic Society pleural disease guideline 2010. Thorax 2010;65:ii18-ii31.

4. Tschopp JM, Bintcliffe O, Astoul P, et al. ERS task force statement: diagnosis and treatment of primary spontaneous pneumothorax. Eur Respir J 2015;46:321-35.

5. Vatish D, Bhowmik A, Rajakulasingam RK. An audit of the management of spontaneous pneumothorax (SP) at UK hospital. Eur Respir J 2016;48:PA661.

6. Bintcliffe OJ, Hallifax RJ, Edey A, et al. Spontaneous pneumothorax: time to rethink management. Lancet 2015;3:578-88.

7. R Development Core Team (2009). R: A language and environment for statistical computing. R Foundation for Statistical Computing, Vienna, Austria. Available online: 
http://www.R-project.org.

8. Hinkle DE, Wierma W, Jurs SG. Applied Statistics for the Behaviour Science. 5th ed. Boston: Houghton Mifflin, 2003.

9. Czerny M, Salat A, Fleck T, et al. Lung wedge resection improves outcomes in stage I primary spontaneous pneumothorax. Ann Thorac Surg 2004;77;1802-5.

10. Gossot D, Galleta D, Stern JB, et al. Result of thoracoscopic pleural abrasion for primary spontaneous pneumothorax. Surg Endosc 2004;18:466-71.

11. Luh SP, Koon WJ, Sn MS, et al. Video- assisted thoracic surgery for spontaneous pneumothorax: outcome of 189 cases. Int Surg 2004;89:185-9.

12. Jiang L, Jiang G, Zhu Y, et al. Risk factors predisposing to prolonged air leak after video-assisted thoracoscopic surgery for spontaneous pneumothorax. Ann Thorac Surg 2014;97:1008-13.

13. Chee CBE, Abisheganaden J, Yeo JKS, et al. Persistent air leak in spontaneous pneumothorax - clinical course and outcome. Respir Med 1998;92:757-61.

14. Loubani M, Lynch V. Video assisted thoracoscopic bullectomy and acromycin pleurodesis: an effective treatment for spontaneous pneumothorax. Respir Med 2000;94:888-90.

15. Sahn SA, Heffner JE. Spontaneous pneumothorax. N Engl J Med 2000;342:868-74.

16. Lesur O, Delorme N, Fromaget JM, et al. Computed tomography in the etiological assessment of idiopathic spontaneous pneumothorax. Chest 1990;98:341-7.

17. Bense L, Lewander R, Eklund G, et al. Nonsmoking, non-alpha-1-antitrypsin deficiency induced emphysema

Cite this article as: Dżeljilji A, Karuś K, Kierach A, Kazanecka B, Rokicki W, Tomkowski W. Efficacy and safety of pleurectomy and wedge resection versus simple pleurectomy in patients with primary spontaneous pneumothorax. J Thorac Dis 2019;11(12):5502-5508. doi: 10.21037/jtd.2019.11.28 in nonsmokers with healing spontaneous pneumothorax, identified by computed tomography of the lungs. Chest 1993;103:433-8.

18. Mitlehner W, Friedrich M, Dissmann W. Value of computed tomography in the detection of bullae and blebs in patients with primary spontaneous pneumothorax. Respiration 1992;59:221-7.

19. Noppen M, Dekeukeleire T, Hanon S, et al. Fluoresceinenhanced autofluorescence thoracoscopy in patients with primary spontaneous pneumothorax and normal subjects. Am J Respir Crit Care Med 2006;174:26-30.

20. Gotoh M, Yamamoto Y, Igai H, et al. Clinical application of infrared thoracoscopy to detect bullous or emphysematous lesions of lung. J Thorac Cardiovasc Surg 2007;134:1498-501.

21. Bridevaux PO, Tschoop JM, Cardillo G, et al. Shortterm safety of thoracoscopic talc pleurodesis for recurrent primary spontaneous pneumothorax: a prospective European multicentre study. Eur Respir J 2011;38:770-3.

22. Chen JS, Chan WK, Yang PC. Intrapleural minocycline pleurodesis for the treatment of primary spontaneous pneumothorax. Curr opin Pulm Med 2014;20:371-6.

23. Sepehripour AH, Nasir A, Sjah R. Does mechanical pleurodesis result in better outcomes than chemical pleurodesis for recurrent primary spontaneous pneumothorax? Interact Cardiovasc Thorac Surg 2012;14:307-11.

24. Huh U, Kim YD, Cho JS, et al. The effect of thoracoscopic pleurodesis in primary spontaneous pneumothorax: apical parietal pleurectomy versus pleural abrasion. Korean J Thorac Cardiovasc Surg 2012;45:316-9. 